\title{
Knowledge of Farm Women about Improved Animal Husbandry Practices in Saurashtra Region of Gujarat, India
}

\author{
Diksha Sharma ${ }^{1}$, Nidhi ${ }^{2}$, Sonika Sharma ${ }^{3}$ and Devendra Kumar Meena ${ }^{4 *}$ \\ ${ }^{1}$ Department of Extension Education, SKRAU, Bikaner, India \\ ${ }^{2}$ Krishi Vigyan Kendra, Maulasar, Nagour, India \\ ${ }^{3}$ Department of Extension Education, MPUAT, Udaipur, India \\ ${ }^{4}$ Department of Extension Education, COA, Bharatpur, India \\ *Corresponding author
}

\section{Keywords \\ Farm women, Improved animal husbandry and knowledge}

\section{Article Info}

Accepted: 08 July 2018 Available Online: 10 August 2018

\section{A B S T R A C T}

The present study was conducted in Gujarat. The investigation concerned with Saurashtra Region of Gujarat Animal husbandry is the main occupation and Maximum agriculture and animal husbandry practices are followed by the farm women in research area. India occupies the foremost position among the countries of world in respect of livestock. Livestock is an important segment of agriculture in India as it makes bread and butter for small and marginal farmers in country. Animal Husbandry and Dairying may be regarded as a source to create the employment in rural areas all-round the year. Agriculture sector also provides fodder for livestock. Cow and buffalo provide protective food in the form of milk and they also provide draught power for farm operations. More than three fourth of the labour demand in livestock production is met by women. This is one sector where poor contributes to the growth directly instead of getting benefit from growth generated elsewhere. In spite of active involvement of women in different animal husbandry activities, lack of exposure and assess to new technology has restricted women to show their full potential for the growth of livestock sector. It has been estimated that about 86 per cent of the total rural women are working for various agricultural operations therefore study conducted in Gujarat. Hence, an investigation entitled "Knowledge of Farm Women About improved Animal Husbandry Practices in Saurashtra Region of Gujarat" was conducted by random sampling technique selected 120 dairy women with a condition that the respondent has been rearing animals on their farm at least three years or having herd were taken as respondents of Junagadh and Gir Somnath districts in Sauratshra Region of Gujarat.

\section{Introduction}

India occupies the foremost position among the countries of world in respect of livestock. Livestock is an important segment of agriculture in India as it makes bread and butter for small and marginal farmers in country. India ranks first in milk production, accounting for 18.5 per cent of world production, achieving an annual output of 165.4 million tons during 2016-17 as compared to 155.5 million tons during 2015- 
2016 recording a growth of 6.26 per cent. Whereas, the Food and Agriculture Organization (FAO) has reported a 3.1 per cent increase in world milk production. The per capita availability of milk in India has increased from 176 grams per day in 19901991 to 355 grams per day by 2016-17. It is more than the world average of 294 grams per day.

Animal husbandry is an integral component of Indian agriculture supporting livelihood of more than two-thirds of the rural population. The adage of "except the cry of the animal nothing goes waste" is perfectly valid looking to the role of animal husbandry in agrarian economy. Agricultural wastes and by products forms the major input required for livestock production, which enable effective disposal of those items, which are otherwise wasted and even causes disposal problems. In return animal provide draught power for crop production. Farmyard manure has great role in maintaining fertility of soil by increasing aeration and humus and is devoid of consequences of animal chemical fertilizer.

Agriculture sector provides strength of Indian economies which significantly contributes to GDP and provides employment to more than 60 per cent of its population. But due to certain mischance like drought and other calamities, it is enable to provide only 200 days employment to a rural person. In as much as, rural families depend on livestock rearing for supplementary income. Apart from providing a subsidiary income to the families, rearing of livestock such as cattle, buffaloes, sheep, goats, pigs, poultry etc. is a source of nutrition in the form of milk, eggs and meat. It has been found that in the time of exigencies like drought and other natural calamities, it is the livestock, which comes to the rescue of the vast sections of rural population. Livestock contributed 16 per cent to the income of small farm households as against an average of 14 per cent for all rural households. It also provides employment to about 8.8 per cent of the population in India.

Animal Husbandry \& Dairying may be regarded as a source to create the employment in rural areas all-round the year. Agriculture sector also provides fodder for livestock. Cow and buffalo provide protective food in the form of milk and they also provide draught power for farm operations. Moreover, it also meets the food requirements of the people. Animal husbandry promotes gender equity. More than three fourth of the labour demand in livestock production is met by women. This is one sector where poor contributes to the growth directly instead of getting benefit from growth generated elsewhere.

The crucial role of women in agriculture and allied activities has been grossly under estimated and undervalued. However, many of the important tasks in animal husbandry are performed by women besides their responsibilities as home makers and caring of animals is considered as an extension of domestic activities. It is estimated that 600 million poor livestock keepers in the world, around two-thirds are women and most live in rural areas (Thornton et al., 2002).

Rural women are also responsible for collection, preparing dung cakes an activity that also brings additional income to poor families. Evidently, rural women are involved in almost all livestock related activities. Except grazing, all other livestock management activities are mainly performed by females. Majority of women are involved in shed cleaning and collection of farm yard manure chopping of fodder, feeding, cleaning, milking of animals, goat rearing, backyard poultry etc. However, males share the responsibility of taking care of sick animals. It is evident that the women are playing a dominant role in the livestock production and 
management activities. The credit of growth in the livestock sector goes to women.

In spite of active involvement of women in different animal husbandry activities, lack of exposure and assess to new technology has restricted women to show their full potential for the growth of livestock sector. It has been estimated that about 86 per cent of the total rural women are working for various agricultural operations (Patel et al., 2016).

Hence upon, it is said that adequate training is necessary for gaining knowledge in any field which is essential for acceptance and adoption of any ideas. Training provides a systematic improvement of knowledge and skills which in turn helps the trainees to function effectively and efficiently in their given task on completion of the training. Women spent mainly $5.17 \mathrm{hrs}$. in out of total $6.76 \mathrm{hrs}$. for animal husbandry activities (Malik et al., 2015).

Training here refers to knowledge of facts and practices possessed by farm women. Training plays an important role in the advancement of human performance in a given situation. Training provides a systematic improvement of knowledge and skills which in turn helps the trainees to function effectively and efficiently in their given task on completion of the training.

In India, extension functionaries of development department concerned with animal husbandry department are engaged in imparting technical knowledge related to production of animal husbandry to the milk producers.

\section{Materials and Methods}

The study was conducted in Junagadh and Gir Somnath district of Sauratshra Region of Gujarat state was purposively selected. Two taluka from each selected from each selected districts. Three villages were selected purposively from the each selected taluka having more population of cattle and buffalo, by selecting 10 from each selected village were taken by using random sampling technique with a condition that the respondent has been rearing animals on their farm at least 3 years or having herd total 120 respondents.

\section{Result and Discussion}

\section{Knowledge level of farm women about} improved animal husbandry practices

Knowledge level of farm women regarding different areas of livestock management practices was measured on four aspects namely, breeding, feeding, management and health care. The findings regarding knowledge level in various aspects have been presented and discussed as under:

\section{Distribution of respondents according their knowledge about Animal Breeds}

Knowledge level of farm women about improved animal breeds was illustrated in Table 1.

It is worth to noted that women live in rural area might be found more traditional so that they were not adopting improved breed of cow like Holstein Friezian and Jersey.

\section{Knowledge about feeding and fodder}

The data presented in Table 2 lighted knowledge levels of farm women about balanced feeding. Perusal of data in the Table 2 revealed that feeding is most important and complex aspect of dairy farming management. Overall, about feeding practices in dairy farming, majority (75.84 per cent) of respondents had medium level knowledge followed by 12.50 per cent and 11.66per cent 
had high and low knowledge, respectively. This might be due to lack of interest of farm women in feeding management and lack of knowledge about the methods of conservation of feed, urea treatment over the feed to enhance its nutritive value and likewise feeding management practices particularly during summer and in scarcity. Findings were reported by (Mankar et al., 2011), (Solanki et al., 2011), (Parjapati et al., 2015), (Kaur and Rathore, 2014).

\section{Knowledge about breeding practices}

Showed in Table 3 data about knowledge of farm women about improved breeding practices. It is evident from Table 3 that in dairy farming majority $(84.16 \%)$ of respondents had medium level of knowledge followed by 15.84 per cent low level of knowledge. There was no high level of knowledge about breeding practices.

Which is due to fact that majority of farmwomen understood the importance of knowledge of accurate and timely heat detection, A.I. / natural service at proper time of heat and pregnancy diagnosis at 60-90 days after A.I. / natural service, for better breeding efficiency of dairy animals but lack of contact with veterinary surgeons/ staffs because of high cost involved in calling them for treatment of breeding related problems, lack of Artificial Insemination (A.I.) centres, ill equipped and poor services at A.I. centres and distant location of veterinary hospital/ A.I. centres discourage them to adopt improved breeding practices. This result is confined to findings by (Prajapati et al., 2015), (Akhtar et al., 2013), (Singh et al., 2013) and (Kaur and Rathore, 2014).

\section{Knowledge about dairy management practices}

Knowledge level of farm women presented in Table 4 about various dairy management practices. It is depicted from Table 4 that majority $(70.84 \%)$ of farm women regarding management practices had medium knowledge level followed by 20.83 and 8.33 per cent low and high level of knowledge, respectively.

It was found that majority 91.67 per cent of farm women belong to medium to low category. The probable reason might be that housing facility are less because of poor economic condition and depends only agriculture and dairy for their livelihood. Only 8.33 per cent farm women had high level of knowledge about housing facility. This finding is in line with those reported by (Singh et al, 2005), (Sharma et al, 2009), (Patil et al., 2009), (Prajapati et al., 2015), (Singh et al., 2013) and (Kaur and Rathore 2014) (Fig. 1).

Table.1 Distribution of respondents according to knowledge about animal breed

$(\mathbf{n}=120)$

\begin{tabular}{|l|c|c|c|}
\hline \multicolumn{2}{|c|}{$\begin{array}{c}\text { Sr. } \\
\text { No. }\end{array}$} & Knowledge about animal breed & \multicolumn{2}{|c|}{ Farm women } \\
\cline { 3 - 4 } & Frequency & Percentage \\
\hline $\mathbf{1}$ & Low knowledge (less than0.23 score) & 36 & 30.00 \\
\hline $\mathbf{2}$ & Medium knowledge (0.23 to 1.16 score) & 84 & 70.00 \\
\hline $\mathbf{3}$ & High knowledge (above 1.16 score) & 00 & 00.00 \\
\hline & Total & $\mathbf{1 2 0}$ & $\mathbf{1 0 0 . 0 0}$ \\
\hline
\end{tabular}


Table.2 Distribution of respondents according to knowledge on feeding and fodder

$(\mathbf{n}=\mathbf{1 2 0})$

\begin{tabular}{|l|l|l|l|}
\hline \multirow{2}{*}{ Sr. No. } & \multirow{2}{|l|}{} & \multicolumn{2}{|l|}{ Farm women } \\
\cline { 3 - 4 } & Knowledge on Feeding and fodder & Frequency & Percentage \\
\hline $\mathbf{1}$ & Low knowledge (less than 2.23 score) & 14 & 11.66 \\
\hline $\mathbf{2}$ & Medium knowledge (2.23 to 5.98 score) & 91 & 75.84 \\
\hline $\mathbf{3}$ & High knowledge (above 5.98 score) & 15 & 12.50 \\
\hline & Total & $\mathbf{1 2 0}$ & $\mathbf{1 0 0 . 0 0}$ \\
\hline
\end{tabular}

Table.3 Distribution of respondents according to knowledge on breeding

$(\mathbf{n}=120)$

\begin{tabular}{|l|c|c|c|}
\hline \multirow{2}{*}{$\begin{array}{c}\text { Sr. } \\
\text { No. }\end{array}$} & Knowledge on breeding & \multicolumn{2}{|c|}{ Farm women } \\
\hline $\mathbf{1}$ & Low knowledge(less than 4.46 score) & 19 & 15.84 \\
\hline $\mathbf{2}$ & Medium knowledge(4.46 to 6.58) & 101 & 84.16 \\
\hline $\mathbf{3}$ & High knowledge (above 6.58 score) & 00 & 00.00 \\
\hline & Total & $\mathbf{1 2 0}$ & $\mathbf{1 0 0 . 0 0}$ \\
\hline
\end{tabular}

Table.4 Distribution of respondents according to knowledge on dairy management practices

$(\mathbf{n}=\mathbf{1 2 0})$

\begin{tabular}{|l|l|c|c|}
\hline \multirow{2}{*}{$\begin{array}{c}\text { Sr. } \\
\text { No. }\end{array}$} & Knowledge on dairy management & \multicolumn{2}{|c|}{ Farm women } \\
\hline $\mathbf{1}$ & Low knowledge (less than 2.49 score) & Frequency & Percentage \\
\hline $\mathbf{2}$ & Medium knowledge (2.49 to 6.03 score) & 85 & 20.83 \\
\hline $\mathbf{3}$ & High knowledge (above 6.03 score) & 10 & 08.83 \\
\hline & Total & $\mathbf{1 2 0}$ & $\mathbf{1 0 0 . 0 0}$ \\
\hline
\end{tabular}


Table.5 Distribution of respondents according to knowledge on health care

$(\mathbf{n}=\mathbf{1 2 0})$

\begin{tabular}{|l|l|c|c|}
\hline \multicolumn{1}{|c|}{$\begin{array}{c}\text { Sr. } \\
\text { No. }\end{array}$} & Knowledge on health care & \multicolumn{2}{|c|}{ Farm women } \\
\hline $\mathbf{1}$ & Low knowledge (less than 0.05 score) & 11 & 9.16 \\
\hline $\mathbf{2}$ & Medium knowledge (0.05 to 1.16 score) & 91 & 75.83 \\
\hline $\mathbf{3}$ & High knowledge (above 1.16score) & 18 & 15.00 \\
\hline & Total & $\mathbf{1 2 0}$ & $\mathbf{1 0 0 . 0 0}$ \\
\hline
\end{tabular}

Table.6 Distribution of respondents according to knowledge on marketing

$(\mathbf{n}=120)$

\begin{tabular}{|l|l|c|c|}
\hline \multicolumn{1}{|c|}{$\begin{array}{c}\text { Sr. } \\
\text { No. }\end{array}$} & Knowledge on marketing & \multicolumn{2}{c|}{ Farm women } \\
\hline $\mathbf{1}$ & Low knowledge (less than 1.99 score) & Frequency & Percentage \\
\hline $\mathbf{2}$ & Medium knowledge(1.99to 3.73 score) & 98 & 6.67 \\
\hline $\mathbf{3}$ & High knowledge (above 3.73 score) & 14 & 81.67 \\
\hline & Total & $\mathbf{1 2 0}$ & 11.66 \\
\hline
\end{tabular}

Table.7 Distribution of respondents according to overall knowledge about improved animal husbandry practices

$(\mathbf{n}=\mathbf{1 2 0})$

\begin{tabular}{|l|l|c|c|}
\hline \multirow{2}{*}{$\begin{array}{c}\text { Sr. } \\
\text { No. }\end{array}$} & Knowledge & \multicolumn{2}{|c|}{ Farm women } \\
\hline $\mathbf{1}$ & Low knowledge (less than 13.44 score) & Frequency & Percentage \\
\hline $\mathbf{2}$ & Medium knowledge (13.44to 24.55 score) & 79 & 20.83 \\
\hline $\mathbf{3}$ & High knowledge (above 24.55 score) & 16 & 65.84 \\
\hline & Total & 120 & 13.33 \\
\hline
\end{tabular}


Fig.1 Distribution of respondents according to overall knowledge about improved animal husbandry practices

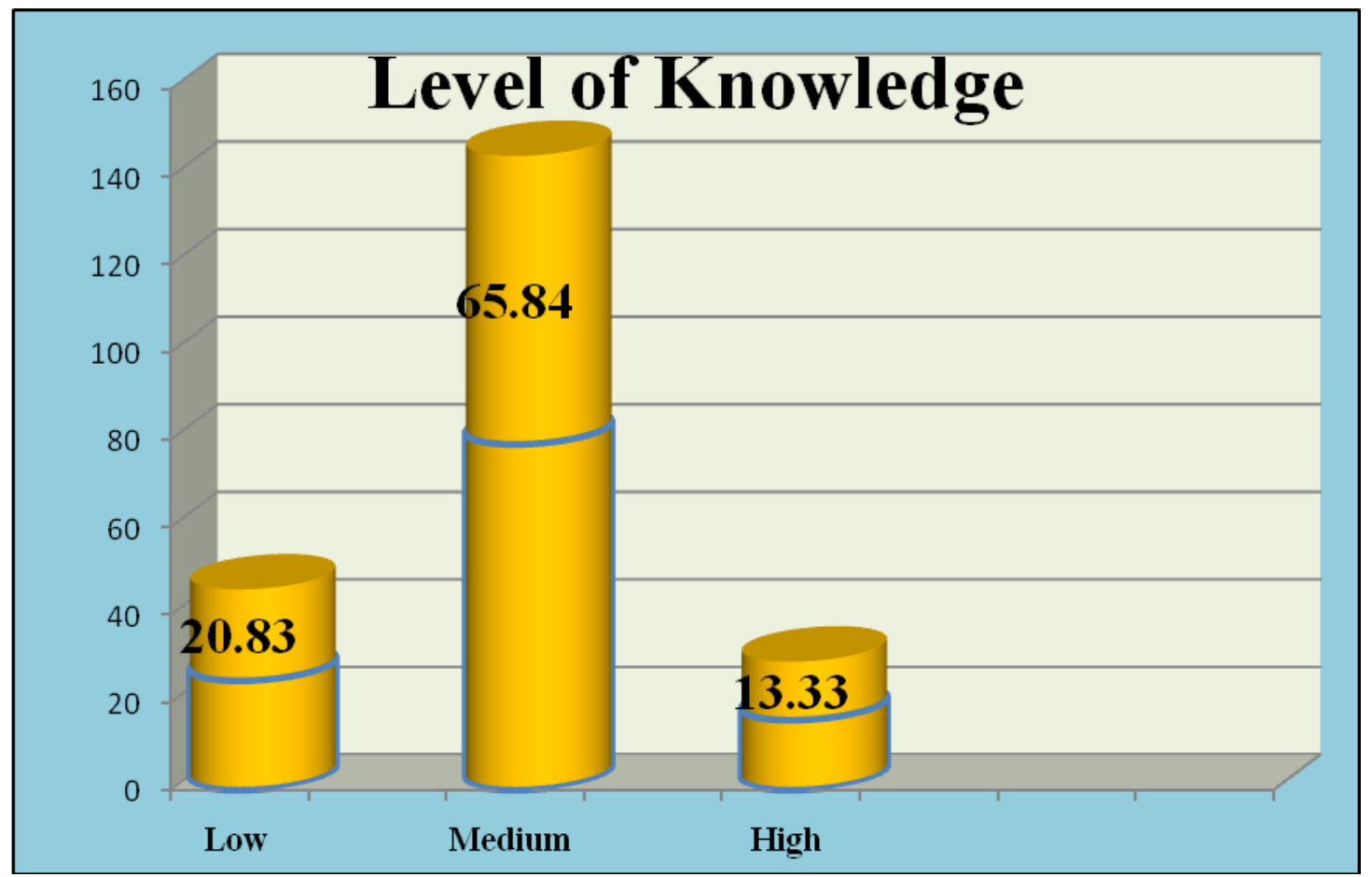

\section{Knowledge about health care practices}

To prevent the dairy animals from infectious disease and care pregnant animal are most important practices in animal husbandry. Data presented in Table 5 showed knowledge level of farm women about improved animal husbandry practices. The data presented in Table 5 visualizes that in the area of health care maximum number of farmers come under medium level of knowledge with 75.83 per cent, followed by 15.00 per cent and 9.16 per cent with high and low level of knowledge, respectively.

This is attributed from the finding of field survey that majority of the farmwomen were aware about the importance of timely and regular vaccination of dairy animals against commonly occurring contagious diseases, prompt reporting of incidence of contagious diseases to Government authority, hygienic disposal of placenta and dead body and proper care and post bite vaccination of dairy animals after dog bite. However, majority of farmwomen failed to understand the significance of regular deworming of dairy animals for maintaining better health and productivity of dairy animals and also about dehorning practices in calves. The finding supported results (Patil et al., 2009), (Solanki et al., 2011), (Prajapati et al., 2012) and (Kaur and Rathore, 2014).

\section{Knowledge about marketing practices}

The data depicted from Table 6 revealed that maximum number of farm women come under medium level of knowledge with 81.67 per cent followed by 11.66 per cent and 6.67 per cent with high and low level of knowledge, respectively.

It is inferred that 93.33 per cent farm women had medium to high level of knowledge about selling of milk and animal because milk 
cooperative society are working in each village, most of women are member of dairy cooperative society, but they found less knowledge in government programme which provide subsidy on dairy farm. The reason behind this is low level of participation and use of mass media.

\section{Overall knowledge about improved animal husbandry practices}

Data related to overall knowledge of farm women about animal breeds, feeding and fodder, breeding, dairy management, health care and marketing practices were illustrated in Table 7. The data presented in same table lighted that overall knowledge about improved animal husbandry practices. It was found that 65.84 per cent farm women had medium level of knowledge about improved animal husbandry practices which is followed by 20.83 per cent low and 13.33 per cent high level of knowledge.

The probable reason for their medium level of knowledge might be due to their medium level of extension contact and mass media exposure, besides their medium level of experience in dairy farming and their primary to secondary level of formal education might have encouraged them to take interest in various awareness programmes run by Junagadh Agriculture University, Sardar Samirti Kendra and state department of agriculture. Here, 20.83 per cent of farmwomen had low level of overall knowledge which is mainly attributed to illiteracy, small herd size and poor economic status and low level of social participation. This finding is supported by result reported by Khokhar (2007) and Patel et al., (2014).

\section{References}

Akhter, Juned; Asiwal, B. L. and Hussain, Akhter. 2013. Knowledge and adoption of animal husbandry practices among the farmers of Sikar district of Rajasthan. Ind. J. Ext. Edu. \& R.D., 2(1): 196-199.

Kaur, R. and Rathore, R. 2014. Knowledge of women regarding dairy farming practices. International Journal of Scientific Research, 3(1):197-198.

Khokhar, S. R. 2007. A study on adoption of dairy innovations by dairy farm women in Anand district. M.Sc. (Agri.) Thesis (Unpublished). Anand Agricultural University, Anand.

Malik, A., Gautam and Kamaldeep. 2015. Relative contribution of rural women to animal husbandry activities in Haryana. Asi. J. Ani. Sci., 10(1): 4348.

Mankar, D. M., Shambharkar, Y. B. and Thakre, R. A. 2011. Multidimensional study of dairy farmers in Vidarbh region. Dairy Industry, 1(3):35-37.

Patel, R. N., Patel, V. T and Prajapati, M. R. 2014. Attitude, Knowledge and Adoption Level of Dairy Farm Women towards Dairy Farming. Guj. J. Ext. Edu., 25 (2): 138-139.

Patel, R. N., Prajapati, M. M., Patel, V. T. 2016. Training Needs of Tribal Women of Sabarkantha District Regarding Animal Husbandry Practices. Guj. J. Ext. Edu., 26 (2): 138-139.

Prajapati, V. S., Singh, R. R, Sandhya, S., Choudhary and Patel N. B.2015. Knowledge Level of Dairy Farmers Regarding Recommended Dairy Management Practices. Livestock Research International. 3(4):82-84.

Sharma, K., Singh, S. P. and Yadav, V. P. S. 2009. Knowledge of dairy farmers about improved buffalo husbandry management practices. Ind. Res. J. Ext. Edu., 9(3):51-54.

Singh, S.P., Pal, A.K. and Goel, S. 2013. Knowledge level of dairy farmers in 
un-adopted villages of Krishi Vigyan Kendra about scientific dairy farming practices. The Journal of Rural and Agricultural Research, 13(2):84-86.

Solanki, D., Upadhyay, R. and Meena, V. 2011. Improved dairy cattle management: technical know-how among rural women. Journal of Community Mobilization and
Sustainable Development, 6(2):185189.

Thornton, P. K., Kruska, R. L., Henninger, N., Kristjanson, P. M., Reid, R. S., Atieno, F., Odero, A. N. and Ndegwa, T. 2002. Mapping poverty and livestock in the developing world. International Livestock Research Institute Nairobi, Kenya.

\section{How to cite this article:}

Diksha Sharma, Nidhi, Sonika Sharma and Devendra Kumar Meena. 2018. Knowledge of Farm Women about Improved Animal Husbandry Practices in Saurashtra Region of Gujarat, India. Int.J.Curr.Microbiol.App.Sci. 7(08):1227-1235.

doi: https://doi.org/10.20546/ijcmas.2018.708.138 